\title{
Exploring the Shift in Children's Incline Motion Predictions: Fragmentation and Integration of Knowledge as Possible Contributors
}

\author{
Michael Hast ${ }^{1}$ \\ ${ }^{1}$ School of Management and Social Sciences, St Mary's University, Twickenham, UK \\ Correspondence: Michael Hast, School of Management and Social Sciences, St Mary's University, Waldegrave \\ Road, Twickenham, TW1 4SX, UK. Tel: 44-020-8240-4366. E-mail: michael.hast@smuc.ac.uk
}

Received: May 12, 2014

Accepted: June 12, $2014 \quad$ Online Published: July 30, 2014

doi:10.5539/jedp.v4n2p74

URL: http://dx.doi.org/10.5539/jedp.v4n2p74

\begin{abstract}
Recent research with primary school children has indicated that while younger children believe a light ball will roll down an incline faster than a heavy ball — matching their beliefs about horizontal motion —older children believe the heavy ball will roll down faster-matching their conceptions about fall. Tentative suggestions regarding the cause of this age shift were made, but no clear conclusion could be reached. The present research aimed to resolve this issue by addressing the subjectivity of children's predictions. Children $(N=210)$ aged 5-11 completed a paper-based task where the trajectories of a heavy and a light ball needed to be contrasted for three motion dimensions - horizontal, fall and incline - to address how trajectory predictions compare. The findings suggest that a declining salience of the horizontal dimension in the reasoning process appears to contribute to the age-related shift. It is proposed that these developmental changes in making predictions about object motion can be explained on the basis of fragmentation and knowledge integration. The importance of this work lies in contributing towards clearer models of how commonsense theories of motion develop across childhood. This, in turn, bears implications for curriculum structures and teaching approaches in primary science.
\end{abstract}

Keywords: commonsense motion theories, incline motion, science education, primary school

\section{Introduction}

Several studies have illustrated that children across a wide range of ages are more likely to predict a heavy object to fall faster than a lighter object (Baker, Murray, \& Hood, 2009; Chinn \& Malhotra, 2002; Hast \& Howe, 2013a, b; Nachtigall, 1982; Sequeira \& Leite, 1992; Van Hise, 1988). Other research has demonstrated that when it comes to reasoning about motion along horizontals children tend to predict a lighter object to be faster than a heavier one (Hast \& Howe, 2013a, b; Howe, 1991, as cited in Howe, 1998; Inhelder \& Piaget, 1958). In both cases reasons mostly centred around object mass, a concept that plays a critical role in reasoning about the physical world (Galili, 2001). These results come as no particular surprise since they adequately reflect the theoretical notions of horizontal motion and fall being psychologically differentiated in reasoning processes (Hayes, 1979; Howe, 1998), and previous work has demonstrated that the same children apply different approaches when reasoning about events involving supported motion along horizontals and when reasoning about motion in fall (Bliss \& Ogborn, 1988; Bliss, Ogborn, \& Whitelock, 1989; Hast \& Howe, 2013a, b; Ogborn, 1985).

A prominent view in trying to understand conceptual development in relation to knowledge about the scientific world is that of fragmentation. Accordingly, knowledge exists in fragments that are loosely connected to provide basic theories on which to make predictions about physical events (Clark, 2006; diSessa, 2013; Hammer \& Elby, 2003; Linn, 2006). It is quite plausible that children's understanding of horizontal motion and of fall would engage some of the same concepts but equally some different concepts as well. For instance, the role of support - or lack there of - would be relevant in both instances, but surface friction may be perceived by children as being more relevant in horizontal motion reasoning and gravity only in fall. As a result, rather than providing a single coherent theory about motion children are actually falling back on quasi-independent ideas that, to some extent, share knowledge fragments but also make use of different fragments from one another.

This differentiation in reasoning processes led to the question how motion down inclines-for which reasoning depends on incorporating elements from both horizontal and vertical motion dimensions - might fit into the 
overall development of theories of motion. Hast and Howe (2013a) demonstrated that children aged 5-7 years largely predicted that a light ball would roll down a slope faster than a heavy ball, mapping onto the same children's predictions about the same objects in horizontal motion, but differing from their fall predictions for those two objects. Older children aged 9-11, on the other hand, largely predicted that the heavy ball would be faster down the slope, but at the same time demonstrated the same beliefs as the younger children regarding both horizontal motion and fall. A shift from light-as-faster to heavy-as-faster in incline motion predictions alongside seemingly stable understanding about horizontal motion and fall was noted. On the basis of further factors, such as children's understanding of incline height changes and their effects on motion, Hast and Howe (2013a) suggested that predictions about incline motion most likely do not represent a third form of understanding but are instead a result of children's use of information about horizontal and vertical dimensions.

This would appear to fit in well with ideas concerning knowledge integration (Linn, 2006; Schneider, 2012; Schneider \& Hardy, 2013; Schneider \& Stern, 2009). Fragmented ideas are interlinked and coordinated within larger configurations of knowledge, and reinforcing such connections over time should result in more systematic forms of reasoning (Thaden-Koch, Dufresne, \& Mestre, 2006; Wagner, 2010). More relevantly, children should be able to take two variables and integrate information about these variables in order to reach a conclusion about an intermediary state. This idea of 'logical congruence' (Kloos, 2007, p. 227) assumes an understanding of how variables are linked and how changing one variable's input affects the expression of another corresponding variable towards a third concept. This can, for instance, be seen with the interrelations between mass, size and density (e.g. Kloos \& Van Orden, 2005) or with the interplay between speed, distance and time (e.g. Howe, Nunes, \& Bryant, 2010). Although developmental trends in such knowledge integration are usually noted, how two related physical dimensions correlate in their interactions seems to be understood fairly early on, by at least 4 to 5 years of age (cf. Kloos \& Amazeen, 2005). Clearly, this is something that might be anticipated to occur in the case of knowledge integration of two different motion dimensions and how such an interaction would inform a third outcome - that is, how horizontal and vertical motion might inform motion down inclines.

Hast and Howe (2013a) do not provide further information on how the integration of dimension information in reasoning about motion down inclines might develop across childhood. There is a clear limitation regarding the information that the study made use of. For instance, although both the 5-year-olds and the 11-year-olds predicted that the heavy ball would fall faster than the light ball this is not an indication as to how much faster it is expected to be. No claim concerning the disparity between the speeds of the two balls can be stated, or whether this speed disparity, if it exists, changes with age. Yet this information could provide clearer insight into why the age-related shift noted in incline motion reasoning occurs, particularly if it is the result of integrating knowledge about horizontal and vertical motion dimensions. Indeed, age-related changes in disparities in relation to knowledge integration might not be unexpected. In a study by Wilkening (1981), for instance, 5-year-olds, 10 -year-olds and adults were asked to make predictions about (self-propelled) motion for a set of animals. While all three age groups were able to correctly apply the time-distance interaction (i.e. having to estimate how far each animal would come within a given time), the disparity for predicted speeds between the animals became greater with increasing age. It is difficult to adapt these data since they only provide information regarding self-propelled motion - rather than inanimate objects' motion - along a horizontal. Nonetheless they provide a good motive for additional research in this domain.

To further the understanding of how reasoning about incline motion fits into the development of commonsense theories of motion, one main factor may help clarify this understanding, with which the proposed project concerns itself: Subjectivity of predictions. While there may be research on different choices children make in their reasoning about object motion, based on aspects such as using different object features (e.g. Hast \& Howe, 2012), there is currently no information on the subjectivity of the trajectories themselves. The overarching question sought to be answered within the present research was what subjective judgements primary school aged children make in relation to object speed predictions, with particular attention given to object mass and the differentiation and integration of motion dimensions.

\section{Method}

\subsection{Participants}

Participants were recruited from state primary schools located in the Greater London area. A total sample of 210 children (106 girls) was selected. This included 58 Year 1 children ( 33 girls; age $M=6.22$ years, $S D=0.35$ ), 56 Year 2 children ( 30 girls; age $M=7.19$ years, $S D=0.50$ ), 53 Year 4 children ( 23 girls; age $M=9.14$ years, $S D=$ 0.34 ) and 43 Year 6 children ( 20 girls; age $M=11.25$ years, $S D=0.31$ ). 


\subsection{Design and Materials}

The materials consisted of an A5 booklet and two balls, a white table tennis ball and a dark glass marble. Both balls were approximately $4 \mathrm{~cm}$ in diameter, but the table tennis ball weighed approximately $3 \mathrm{~g}$ while the marble weighed approximately $75 \mathrm{~g}$. The balls were identical in all but colour to the items used in Hast and Howe's (2013a) research. The booklet consisted of 20 pages. The front page provided space for participant information. The remaining pages were divided into three sections, one for each of three motion dimensions (horizontal, incline and fall). Each section's first page had a brief written description of the task. This was followed by five diagrams. In the first diagram, two balls were shown. In the case of fall and incline motion two hands were shown holding the balls; in the case of horizontal motion the end of the incline was shown, with the two balls just having reached the bottom. One ball was black, the other was white - the first represented the glass marble, the second represented the table tennis ball. The anticipated trajectories for the two balls were indicated by a dotted line. In subsequent diagrams only one of the two balls was shown. In the second diagram, the ball was shown as being one quarter along the trajectory, in the third diagram the ball was shown as being halfway along the trajectory, in the fourth diagram as three quarters along the trajectory, and in the final diagram just before the end of the trajectory. For half of the overall sample, the dark ball was shown, and for the other half the white ball was shown. To avoid any order effects, tasks were arranged such that one half of groups worked on fall first and the other half on incline motion first. Horizontal motion had to be considered as a direct result of preceding incline motion and was therefore not subject to task order changes.

\subsection{Procedure}

For the three older age groups the task was carried out with whole classes of around 30 students each. For the Year 1 children the task was broken down into smaller groups of six or seven. The researcher first introduced himself and explained what the task was generally about. Children were then invited to complete their details on the front page of the booklets, with help from the class teachers or assistants where necessary. Following, the researcher asked the children to look at the first diagram in the booklet, which showed both balls. The researcher then presented the two balls to the class or group, making it clear that the black ball in the diagram represented the dark marble and that the white ball in the diagram represented the white table tennis ball. The researcher passed the balls around so that each child had opportunity to handle both balls. No information was given by the researcher regarding the difference in mass between the two balls. The children were then taken through the instructions on the second page of the booklet and were asked to complete the first section's diagrams by drawing in the missing ball. For each of the four diagrams that had one ball missing the children were required to draw the second ball where, at the same point in time as the shown ball, they anticipated the missing ball might be if both balls had started moving at the same time (either through release in the case of fall and incline, or through exiting the incline along the horizontal). Once all children had completed the first section the researcher took them through the second and third sections' instructions in the same manner. The task lasted for approximately 20 minutes per class or group.

\section{Results}

Analyses focused on the distance, in $\mathrm{cm}$, between the shown ball and the drawn ball for each diagram. Distance was measured from the centre of the shown ball to the centre of the drawn ball, in parallel to the trajectory line. The distances were then analysed according to absolute disparity - the difference between the two balls regardless of direction of that difference-and relative disparity, taking into account the direction of difference. Mean differences were analysed with a 4 (age; between-subjects) x 3 (dimension; within-subjects) mixed design analysis of variance and post-hoc $t$-tests. Gender effects, task presentation order effects and ball type effects (i.e. whether it made a difference whether the heavy or the light ball was already shown) were analysed with $t$-tests, but no significant effects were found, therefore these factors will not be considered further. All data were analysed using SPSS version 21.

No significant main effects of age or dimension and no significant age $\mathrm{x}$ dimension interaction were noted for absolute disparity measures. That is to say, the mean difference between the shown ball and the drawn ball - regardless of direction of difference between the two balls - did not significantly vary across the three dimensions or across the four age groups. For relative disparity, on the other hand, significant main effects of age, $F(3,206)=5.61, p<.05, \eta_{\mathrm{p}}^{2}=.08$, and dimension, $F(2,412)=96.41, p<.001, \eta_{\mathrm{p}}^{2}=.32$, were noted, as well as a significant age $\mathrm{x}$ dimension interaction, $F(6,412)=3.08, p<.05, \eta_{\mathrm{p}}^{2}=.04$. Figure 1 shows the mean relative disparities by motion dimension and age, with the $\mathrm{x}$-axis denoting the trajectory of the light ball (Note 1 ). 


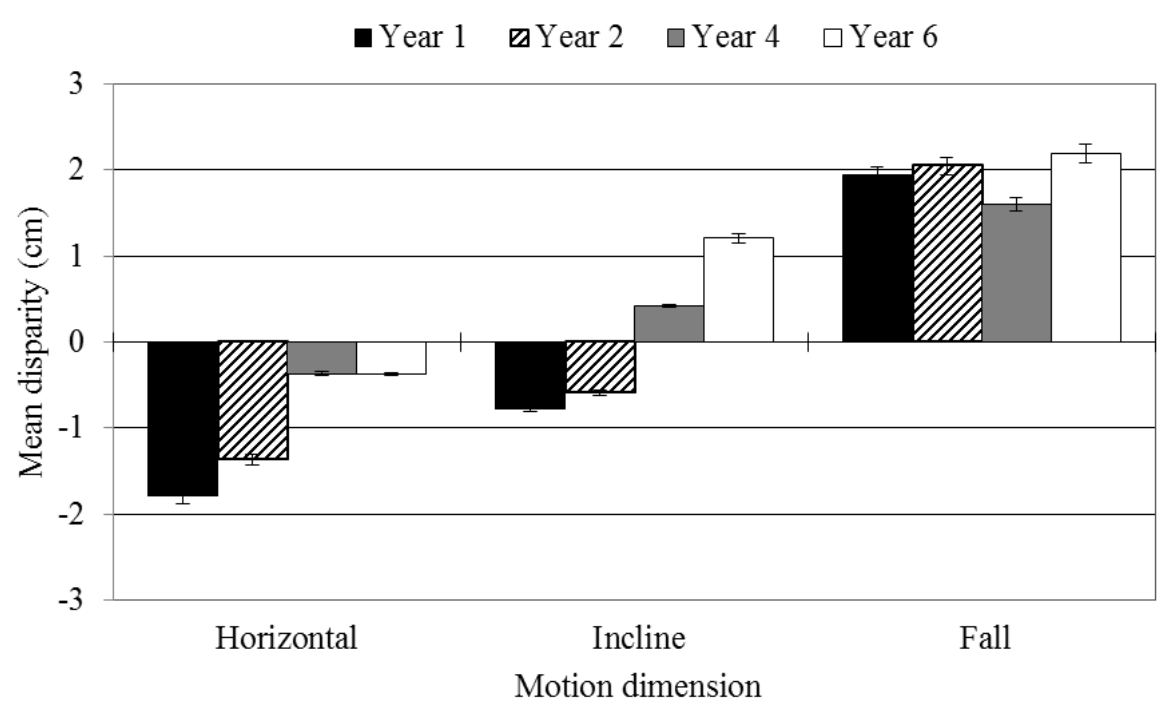

Figure 1. Mean relative disparity by motion dimension and age, the $\mathrm{x}$-axis denotes the trajectory of the light ball

Regarding the main effect of age, regardless of dimension, mean relative disparities were only found to be significantly different between Year $2(M=0.17 \mathrm{~cm}, S D=1.27)$ and Year $4(M=-0.55 \mathrm{~cm}, S D=1.95), t(107)=$ $5.53, p<.05, r=.47$. These results indicate strong overall similarity between Years 1 and 2 and between Years 4 and 6 but point to a crucial change between these two groups. Regarding the main effect of dimension, regardless of age, mean relative disparities were significantly different between horizontal $(M=-1.04 \mathrm{~cm}, S D=$ $2.31)$ and incline $(M=-0.03 \mathrm{~cm}, S D=2.84)$ dimensions, $t(209)=5.14, p<.001, r=.33$, and significantly different between incline and fall $(M=1.94 \mathrm{~cm}, S D=2.09)$ dimensions, $t(209)=8.44, p<.001, r=.50$. These results indicate a clear differentiation between the three dimensions.

Regarding the age $\mathrm{x}$ dimension interaction, mean relative disparities became smaller with increasing age, indicating a shift towards a significantly smaller disparity but in the same direction. Specifically, however, the difference between age groups was only significant between Year $2(M=-1.37 \mathrm{~cm}, S D=1.91)$ and Year $4(M=$ $-0.37 \mathrm{~cm}, S D=2.48), t(107)=2.38, p<.05, r=.22$, but not between Years 1 and 2 or between Years 4 and 6 . For incline motion mean relative disparity changed from a negative value, which indicates the light ball was predicted to be faster than the heavy ball, to a positive value, which indicates the heavy ball was predicted to be faster. However, again the difference between age groups was only significant between Year $2(M=-0.63 \mathrm{~cm}$, $S D=2.56)$ and Year $4(M=0.42 \mathrm{~cm}, S D=2.79), t(107)=2.05, p<.05, r=.19$, but not between Years 1 and 2 or between Years 4 and 6 . No significant variation was noted among mean relative disparities across age groups for fall, suggesting stability in reasoning across all four age groups.

\section{Discussion}

The present study aimed to further the understanding of how commonsense theories of motion develop throughout childhood, by addressing the relationship between motion dimensions in making predictions, but specifically the age-related shift in incline motion reasoning previously observed. The children tested in this study largely demonstrated the belief that the heavy ball would fall faster than the light ball, with no significant variation across ages, mapping onto extensive research (Baker et al., 2009; Chinn \& Malhotra, 2002; Hast \& Howe, 2013a, b; Nachtigall, 1982; Sequeira \& Leite, 1992; van Hise, 1988). At the same time, the children mostly expressed that the light ball would roll faster along the horizontal than the heavy ball, again mostly matching previous work (Hast \& Howe, 2013a, b; Howe, 1991, as cited in Howe, 1998; Inhelder \& Piaget, 1958). The fact that the same children reasoned about the same objects in different ways is not surprising, since the two dimensions appear to be psychologically differentiated in reasoning processes (cf. Hayes, 1979; Howe, 1998). This also reflects the idea of knowledge being fragmented, or at least representing quasi-independent ideas (Clark, 2006; diSessa, 2013; Hammer \& Elby, 2003; Linn, 2006).

It is worth noting that ideas about fall seemed to be quite stable across the age groups, indicating no significant changes in how much faster the heavy ball, on average, should be than the light ball. Conversely, the horizontal 
motion predictions showed a decline in mean disparity with increasing age. As a whole, the Year 6 children still mostly believed, like the Year 1 children, that the light ball would be faster, but on average it was not predicted to be much faster in comparison to what the Year 1 children seemed to believe. This is an interesting observation that appears to possibly tie in with some findings outlining differences in opinion regarding horizontal motion predictions in participants older than 12 years, where some appear to associate faster motion with lighter objects (Maloney, 1988) and some with heavy objects (Howe 1991, as cited in Howe, 1998; Inhelder \& Piaget 1958). It would be interesting to see how the developmental trend regarding horizontal motion predictions would have continued beyond the present age groups and whether a cross-over as for incline motion predictions might have been observed. Future research could address this.

Turning to incline motion reasoning identified in previous work (Hast \& Howe, 2013a, b), the age-related shift in predictions is evident here, too. The previous work suggested a combined role of horizontal and vertical elements in incline motion reasoning but could not provide clear support for this notion. The current results, on the other hand, illustrate that relative disparities change with age. Most notably, they do so in parallel to the significant changes noted for horizontal motion predictions. So how can the findings be explained and what contributions may fragmentation and knowledge integration be making in the development of commonsense theories of motion?

A first plausible option is that children may be moving from using a single variable in their decision making towards a more systematic incorporation of multiple variables. Indeed, such effects have been noted in mathematical research (e.g. Baroody, Lai, Li, \& Baroody, 2009; Howe et al., 2010; Wilkening, 1981). Howe and colleagues, for instance, noted that younger children were more likely to make inferences about speed on the basis of distance alone whereas older children demonstrated a more competent integration of time as well. However, it is quite possible that even the youngest children may already be integrating and coordinating information (cf. Kloos \& Amazeen, 2005) and that mathematical concepts, unlike physical everyday events, may be too abstract to allow for knowledge integration at such an early age.

In relation to knowledge integration (Linn, 2006; Schneider, 2012; Schneider \& Hardy, 2013; Schneider \& Stern, 2009), it would seem that as children are making less use of the horizontal motion dimension they are equally aligning their incline motion predictions with their fall predictions. However, these predictions never reach the same disparity level as horizontal or incline alone, suggesting that it is unlikely children are only relying on one source of knowledge alone. This would also argue against the preceding explanation based on mathematics research. Admittedly, it is at this point difficult to fully conclude on the aspect of knowledge integration. As a limitation, children were not explicitly asked to consider the relationship between the three motion dimensions, only the relationship between the objects themselves, and none of the explanations provided by children during the data collection process addressed the interplay. Questioning children about dimension interplay in future research may provide a clearer picture on whether they are indeed integrating knowledge from both dimensions or using a third dimension (though unlikely; cf. Hast \& Howe, 2013a).

If assuming that children are already integrating knowledge from 5 years onwards, the question to address would perhaps be how the importance of information changes throughout development. Previous literature points to the fact that, in direct relation to fragmentation and integration, magnitudes of influence may change over time (Clark \& Linn, 2013). Given the high perceptual similarity between horizontal motion and motion down inclines, that is, having a supported surface in both cases, it may be possible that the horizontal element has more saliency in younger children's reasoning processes than in older children's. It has been noted that younger children tend to rely more on visual aspects in their reasoning about physical events rather than on conceptual factors, with trends towards making use of more conceptual knowledge at later ages (e.g. Hast \& Howe, 2012; Leuchter, Saalbach, \& Hardy, 2014). The salience of the visual element of an incline (i.e. the supported surface) would therefore, plausibly, have a stronger impact on knowledge integration for younger children. Combined with the observations about horizontal motion predictions, this seems a likely candidate for explaining the shift in incline motion reasoning.

A key factor in evaluating the present findings is the role of educational experience affecting the formulation of conceptual understanding (Vosniadou, 2013). Although due to be replaced by a new curriculum, the National Curriculum for England, Wales and Northern Ireland (DfEE, 1999) was still directly relevant to the current sample. It outlined that children aged 5-7 years should be taught about elements related to motion along the horizontal and children aged 8-12 years about gravity and air resistance in fall. This specific focus on each dimension (or lack of focus on the horizontal dimension in the second age group) could help explain the 
developmental shift, particularly the significant change between Years 2 and 4. Everyday experiences appear to influence understanding of fall in particular, suggesting higher stability early on. In comparison, young children show a much wider range of reasoning for horizontal motion, suggesting the understanding may not be fully stable (Hast \& Howe, 2012). The initial focus on horizontal motion in formal teaching may result in children combining information from both dimensions but with more explicit emphasis placed on the role of the horizontal. Subsequently, when the teaching focus shifts to fall the emphasis on the role of horizontal motion in the integration process may become less significant. As a whole, this provides further support for previously raised suggestions regarding the organisation of teaching in relation to differentiation and integration of motion dimensions (Hast \& Howe, 2013a).

It is probable that everyday experiences and formal education amalgamate in the formation of commonsense theories of motion. More crucially, both horizontal and vertical elements appear to play a role in making predictions about incline motion across all age groups, but the role of each dimension changes in the reasoning process as children advance. The research presented here demonstrates how children may develop stronger systematic integration of knowledge about two dimensions to infer about a third outcome but equally points to limitations in the interpretations. This is most notable with the youngest children where it is less clear whether knowledge integration does take place or not. However, given the significant impact formal instruction may have had on the age group it would be worthwhile to focus future research on how pre-schoolers, without formal teaching experience of either horizontal motion or fall, use the dimensions to reason about incline motion.

\section{Acknowledgments}

Part of this work was presented at the 6th World Conference on Educational Sciences in Floriana, Malta. The author would like to thank the participating schools and children for their support.

\section{References}

Baker, S. T., Murray, K., \& Hood, B. M. (2009, April). Children's expectations about weight and speed in falling objects: The younger the judge, the better? Poster presented at the biennial meeting of the Society for Research in Child Development, Denver, CO.

Baroody, A. J., Lai, M.-L., Li, X., \& Baroody, A. E. (2009). Preschoolers' understanding of subtraction-related principles. Mathematical Thinking and Learning, 11, 41-60. http://dx.doi.org/10.1080/10986060802583956

Bliss, J., \& Ogborn, J. (1988). A common-sense theory of motion: Issues of theory and methodology examined through a pilot study. In P. J. Black, \& A. M. Lucas (Eds.), Children's informal ideas in science (pp. 120-133). London: Routledge.

Bliss, J., Ogborn, J., \& Whitelock, D. (1989). Secondary school pupils' commonsense theories of motion. International Journal of Science Education, 11, 261-272. http://dx.doi.org/10.1080/0950069890110303

Chinn, C. A., \& Malhotra, B. A. (2002). Children's responses to anomalous scientific data: How is conceptual change impeded? Journal of Educational Psychology, 94, 327-343. http://dx.doi.org/10.1037/0022-0663.94.2.327

Clark, D. B. (2006). Longitudinal conceptual change in students' understanding of thermal equilibrium: An examination of the process of conceptual restructuring. Cognition and Instruction, 24, 467-563. http://dx.doi.org/10.1207/s1532690xci2404_3

Clark, D. B., \& Linn, M. C. (2013). The knowledge integration perspective: Conncections across research and education. In S. Vosniadou (Ed.), International handbook of research on conceptual change (2nd ed., pp. 520-538). London: Routledge.

DFEE. (1999). The national curriculum for England: Science. London: HMSO.

diSessa, A. A. (2013). A bird's-eye-view of the "pieces" vs. "coherence" controversy (from the "pieces" side of the fence). In S. Vosniadou (Ed.), International handbook of research on conceptual change (2nd ed., pp. 31-48). London: Routledge.

Galili, I. (2001). Weight versus gravitational force: Historical and educational perspectives. International Journal of Science Education, 23, 1073-1093. http://dx.doi.org/10.1080/09500690110038585

Hammer, D., \& Elby, A. (2003). Tapping epistemological resources for learning physics. Journal of the Learning Sciences, 12, 53-90. http://dx.doi.org/10.1207/S15327809JLS1201_3 
Hast, M., \& Howe, C. (2012). Understanding the beliefs informing children's commonsense theories of motion: The role of everyday object variables in dynamic event predictions. Research in Science \& Technological Education, 30, 3-15. http://dx.doi.org/10.1080/02635143.2011.653876

Hast, M., \& Howe, C. (2013a). Towards a complete commonsense theory of motion: The interaction of dimensions in children's predictions of natural object motion. International Journal of Science Education, 35, 1649-1662. http://dx.doi.org/10.1080/09500693.2011.604685

Hast, M., \& Howe, C. (2013b). The development of children's understanding of speed change: A contributing factor towards commonsense theories of motion. Journal of Science Education and Technology, 22, 337-350. http://dx.doi.org/10.1007/s10956-012-9397-5

Hayes, P. J. (1979). The naïve physics manifesto. In D. Michie (Ed.), Expert systems in the micro-electronic age (pp. 242-270). Edinburgh: Edinburgh University Press.

Howe, C., Nunes, T., \& Bryant, P. (2010). Intensive quantities: Why they matter to developmental research. British Journal of Developmental Psychology, 28, 307-330. http://dx.doi.org/10.1348/026151009X410362

Howe, C., Tolmie, A., \& Rodgers, C. (1992). The acquisition of conceptual knowledge in science by primary school children: Group interaction and the understanding of motion down an incline. British Journal of Developmental Psychology, 10, 113-130. http://dx.doi.org/10.1111/j.2044-835X.1992.tb00566.x

Howe, C. J. (1998). Conceptual structure in childhood and adolescence: The case of everyday physics. London: Routledge. http://dx.doi.org/10.4324/9780203440780

Inhelder, B., \& Piaget, J. (1958). In A. Parsons, \& S. Milgram (Trans.), The growth of logical thinking from childhood to adolescence. London: Routledge \& Kegan Paul. http://dx.doi.org/10.1037/10034-000

Kloos, H. (2007). Interlinking physical beliefs: Children's bias towards logical congruence. Cognition, 106, 227-252. http://dx.doi.org/10.1016/j.cognition.2006.03.005

Kloos, H., \& Amazeen, E. L. (2005). Building blocks of physical knowledge: Can children learn how two dimensions are correlated? Advances in Psychology Research, 38, 79-91.

Kloos, H., \& Van Orden, G. C. (2005). Can a preschooler's mistaken belief benefit learning? Swiss Journal of Psychology, 64, 195-205. http://dx.doi.org/10.1024/1421-0185.64.3.195

Leuchter, M., Saalbach, H., \& Hardy, I. (2014). Designing science learning in the first years of schooling: An intervention study with sequenced learning material on the topic of "floating and sinking". International Journal of Science Education, 36, 1751-1771. http://dx.doi.org/10.1080/09500693.2013.878482

Linn, M. C. (2006). The knowledge integration perspective on learning and instruction. In R. K. Sawyer (Ed.), The Cambridge handbook of the learning sciences (pp. 243-264). Cambridge: Cambridge University Press.

Maloney, D. P. (1988). Novice rules for projectile motion. Science Education, 72, 501-513. http://dx.doi.org/10.1002/sce.3730720409

Nachtigall, D. (1982). Vorstellungen von Fünftkläßlern über den freien Fall [Fifth-grader's conceptions of free fall]. Naturwissenschaften im Unterricht-Physik/Chemie, 30, 91-97.

Ogborn, J. (1985). Understanding students' understandings: An example from dynamics. European Journal of Science Education, 7, 141-150. http://dx.doi.org/10.1080/0140528850070205

Schneider, M. (2012). Knowledge integration in mathematics learning: The case of inversion. Educational Studies in Mathematics, 79, 447-453. http://dx.doi.org/10.1007/s10649-011-9373-7

Schneider, M., \& Hardy, I. (2013). Profiles of inconsistent knowledge in children's pathways of conceptual change. Developmental Psychology, 49, 1639-1649. http://dx.doi.org/10.1037/a0030976

Schneider, M., \& Stern, E. (2009). The inverse relation of addition and subtraction: A knowledge integration perspective. Mathematical Thinking and Learning, 11, 92-101. http://dx.doi.org/10.1080/10986060802584012

Sequeira, M., \& Leite, L. (1991). Alternative conceptions and history of science in physics teacher education. Science Education, 75, 45-56. http://dx.doi.org/10.1002/sce.3730750105 
Thaden-Koch, T. C., Dufresne, R. J., \& Mestre, J. P. (2006). Coordination of knowledge in judging animated motion. Physical Review Special Topics-Physics Education Research, 2, 020107. http://dx.doi.org/10.1103/PhysRevSTPER.2.020107

Van Hise, Y. A. (1988). Student misconceptions in mechanics: An international problem? The Physics Teacher, 26, 498-502. http://dx.doi.org/10.1119/1.2342598

Vosniadou, S. (2013). Conceptual change in learning and instruction: The framework theory approach. In S. Vosniadou (Ed.), International handbook of research on conceptual change (2nd ed., pp. 11-30). London: Routledge.

Wagner, J. F. (2010). A transfer-in-pieces consideration of the perception of structure in the transfer of learning. The Journal of the Learning Sciences, 19, 443-479. http://dx.doi.org/10.1080/10508406.2010.505138

Wilkening, F. (1981). Integrating velocity, time, and distance information: A developmental study. Cognitive Psychology, 13, 231-247. http://dx.doi.org/10.1016/0010-0285(81)90009-8

\section{Note}

Note 1. This choice was made at random; the $\mathrm{x}$-axis denoting the heavy ball would merely have resulted in an inversed display of data without affecting their analysis.

\section{Copyrights}

Copyright for this article is retained by the author, with first publication rights granted to the journal.

This is an open-access article distributed under the terms and conditions of the Creative Commons Attribution license (http://creativecommons.org/licenses/by/3.0/). 